\title{
Urban Cold Chain Logistics B2B/B2C Integration Process Reengineering
}

\author{
Zhenlin Wei ${ }^{1, a}$, Huanle Heng ${ }^{1, b}$ and Ya Gao ${ }^{1, c}$ \\ ${ }^{1}$ School of Traffic and Transportation, Beijing Jiaotong University, Beijing 100044, China. \\ azhlwei@bjtu.edu.cn, b17125660@bjtu.edu.cn, cgaoya_bjtu@163.com
}

\begin{abstract}
Aiming at the problem of high cost and low efficiency of individual distribution of B2C in the current cold chain distribution in cities, this paper analyzes and reengineers urban cold-chain logistics distribution process, on the basis of the existing distribution process, rebuilt process by Petri and BPR theory. Finally, analyzing a case study with Arena simulation technology, which indicates that B2B/B2C integration can improve logistics efficiency and reduce logistics cost.
\end{abstract}

Keywords: B2B, B2C, Petri net, Arena, business process reengineering.

\section{Introduction}

The continuous penetration of Internet technology and the rapid rise of fresh e-commerce have greatly promoted the development of urban cold chain B2C home delivery business. But existing $\mathrm{B} 2 \mathrm{C}$ business orders presents the characteristics of more quantities in small batches resulted in the high delivery cost of the $\mathrm{B} 2 \mathrm{C}$ business and restricted the healthy development of cold chain home delivery market. In contrast, the current cold chain B2B business is relatively mature, and the downstream B customers are mostly large shopping malls, supermarkets, etc., which has stable demand for orders, but the utilization rate of refrigerated trucks in distribution process needs to be improved. So we consider reducing the cost by combining them. At present the study of cold chain logistics mostly concentrated on distribution route optimization in a single pattern and the factors affecting the development of cold chain logistics at home and at abroad, while this paper puts forward to combine two modes, by analyzing the business process of the existing mode of the $\mathrm{B} 2 \mathrm{~B}$ and $\mathrm{B} 2 \mathrm{C}$, pointed out the problems and the business process of $\mathrm{B} 2 \mathrm{~B}$ and $\mathrm{B} 2 \mathrm{C}$ as a whole, finally on the basis of $\mathrm{W}$ company data, based on Arena simulation tools, the model is verified to reduce the cold chain logistics cost and improve efficiency .This paper puts forward the new idea of fused two modes, breaking the previous isolated study of model, and verified its feasibility.

\section{Research Ideas and Methods}

\subsection{Research Ideas}

This paper analyzes the current distribution process of B2B business and B2C business separately and proposes the idea of reengineering $\mathrm{B} 2 \mathrm{~B} / \mathrm{B} 2 \mathrm{C}$ business process. That is, $\mathrm{B} 2 \mathrm{C}$ business is delivered by redundant capacity of $\mathrm{B} 2 \mathrm{~B}$ business, and Petri net business process modeling method is applied to reengineering then the case analysis of Beijing W Food Logistics Co., Ltd. was carried out. The actual process simulation was carried out by simulation tool Arena. It was confirmed that the B2B / B2C integration and distribution process could help to reduce the distribution costs of cold chain logistics enterprises, improve distribution efficiency and improve the full load ratio of cold chain logistics and distribution.

\subsection{Research Methods}

In the process of research, literature method, empirical research, model method and simulation method are used. The related theories of petri net in model method and Arena simulation tools used in simulation method are mainly introduced. 


\subsubsection{Petri net Related Theory}

Petri net is a netting model, including two node types, event and condition. It has roundedness, activity and accessibility. In this paper, we use correlation matrix to verify its behavior characteristics.

2.2.1.1 Basic Structure of Petri Net.

The basic structure of Petri net consists of four kinds, including parallel structure, sequence structure, cyclic structure and concurrent structure.

2.2.1.2 Modeling Steps of Petri Nets.

The modeling steps of Petri net are divided into three steps: clear action and state, element mapping and connection and adjustment of Petri net model.

(1) clear action and state.

Before the establishment of Petri network model, it is necessary to determine the various aspects of the distribution process in content, which means the action, which represent the state, such as the distribution process, cold chain logistics company dispatch center, And the sorting operation is completed, is the state of system resources, and order processing, cargo sorting B2C, B2B work is a dynamic event. The clear action and the state of the resources are the precondition of the mapping of the place and the transition.

(2) element mapping and connection.

According to the pre-determined action and state, relying on the modeling symbol of Petri net, the mapping relationship between the place and the transition is drawn. Based on the connection rules of Petri net and the logical relationship between the place and the transition in the model, the place is connected with the transition correctly.

(3) adjustment of Petri net model.

For the establishment of a complex process model, the corresponding Petri nets model usually needs to be adjusted several times to form a correct model. Therefore, after the Petri nets model is established, the Petri nets model can be rewritten by using reachability graph, correlation matrix and computer simulation the correctness of the established model is tested and it is verified whether it meets the behavioral characteristics of Petri nets such as roundedness, activity and safety. If it cannot fully reflect the features Petri nets should, we need to adjust and perfect the established Petri net model until the model can accurately reflect the operational status of the original operation process.

\subsubsection{Arena}

Arena is a simulation software developed by ROCKWELL SOFTWARE, SIMAN simulation language, high versatility simulation software, with strong academic, widely used in academia, Arena's display interface is very intuitive, you can also use the animation display. The basic modeling process of Arena is as follows:

(1) input analysis.

Input analysis is the preparatory work before the simulation modeling, mainly for data acquisition and processing. This article uses the Arena's built-in input data analyzer to analyze the probability distribution of the data.

(2) establish process model.

The establishment of the process model is about to drag the logic module into the model editing area and edit it. The modules are connected in sequence according to the logical sequence of the events.

(3) determining the simulation parameters

The definition of the simulation data is to set the parameters of the data in accordance with the actual needs of each business, according to the features described by each module.

(4) debugging simulation model and simulation running

After establishing the process model and setting the parameters of each module successfully, Arena will automatically analyze the problem of the established process model, and give the specific error location and error type.

(5) output analysis 
According to the object of our research, the appropriate output results are selected according to the target of the research under different circumstances, and the analysis is carried out selectively.

\section{Establish a Process Reengineering Model}

\subsection{Food Cold Chain B2B / B2C Integration Process Reengineering}

\subsubsection{Analysis of Existing Cold Chain Business Processes}

According to different business models, the main business can be divided into B2B business and $\mathrm{B} 2 \mathrm{C}$ business, and the business process diagram of two kinds of business is drawn.

(1) analysis of urban cold chain B2B business process.

B2B distribution business refers to the cooperation between the third party cold chain logistics enterprises and the upstream one or more suppliers, so as to provide professional cold chain distribution services for downstream B customers such as large supermarkets, chain restaurants, canteens, enterprises and institutions. Distribution goods are usually dairy products, cooked food, fresh fruits and vegetables, bean products, ice cream, seafood and other daily food supplies.

The distribution process of B2B business includes order processing, assembly and vehicle scheduling, sorting operation, inspection and loading, distribution, transportation and signing.

(2) analysis of urban cold chain B2C business process.

Cold chain distribution B2C business, namely home delivery business, home delivery business is a product of the rapid development of economy and the individuation and diversification of customer requirements, high quality, multi batch, small quantities of characteristics. To ensure the quality of distribution service, the elasticity, speed and reliability of distribution are important. The overall distribution process of $\mathrm{B} 2 \mathrm{C}$ is broadly consistent with the $\mathrm{B} 2 \mathrm{~B}$ process

\subsubsection{Urban Cold Chain B2B/B2C Integration Process Reengineering Ideas}

Aiming at the problems in existing separately B2B business and $\mathrm{B} 2 \mathrm{C}$ business distribution process, this paper use the remaining capacity $2 \mathrm{~B}$ distribution of vehicles equipped with small quantities of $2 \mathrm{C}$ business. With the combination between B2B and B2C business, and ultimately should be able to improve the utilization rate of carriage, improve the efficiency of distribution and reduce the cost of logistics distribution.

At present, B2B cold chain distribution business is the main business, and B customers have a large cold chain distribution, and the demand is more fixed. The third party logistics companies in the premise of ensuring the $2 \mathrm{~B}$ cold chain distribution service, equipped with a small number of goods from customers $(\mathrm{C})$.

\subsection{Establishment of Business Process Reengineering Model Based on Petri Net}

(1) establishment of B2B business distribution process model.

On the basis of the above process analysis, the Petri net model of B2B business is established as shown in figure 1.

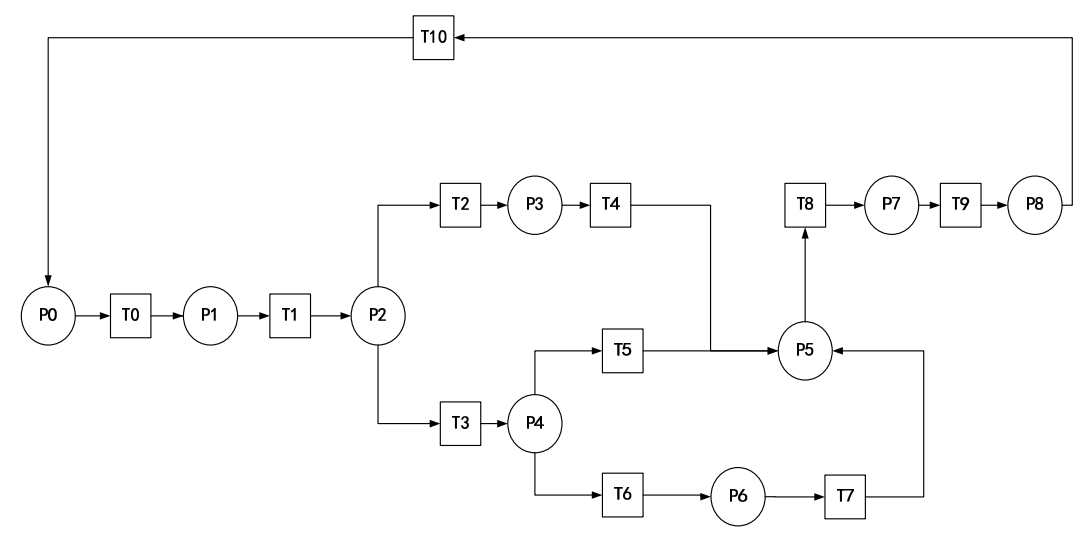

Fig 1. Petri net model of B2B business distribution process 
The contents of the place and the transition elements shown in the figure are shown in table 3-1 as shown in the following table.

Table 1. Meaning of each element in the B2B distribution process of Petri net

\begin{tabular}{cccc} 
Place sign & The connotation of the place & Transition sign & The connotation of the transition \\
\hline $\mathrm{P}_{0}$ & The customer of B2B & $\mathrm{T}_{0}$ & Send B2B demand order \\
$\mathrm{P}_{1}$ & Cold chain logistics company. & $\mathrm{T}_{1}$ & B2B Order processing \\
$\mathrm{P}_{2}$ & scheduling center & $\mathrm{T}_{2}$ & Call available vehicles \\
$\mathrm{P}_{3}$ & Vehicle arrival at the designated loading site & $\mathrm{T}_{3}$ & Generate waybill of B2B \\
$\mathrm{P}_{4}$ & warehouse department. & $\mathrm{T}_{4}$ & Waiting for loading \\
$\mathrm{P}_{5}$ & Check the loading is completed & $\mathrm{T}_{5}$ & Generate B2B loading list. \\
$\mathrm{P}_{6}$ & Completion of sorting & $\mathrm{T}_{6}$ & Sorting operation \\
$\mathrm{P}_{7}$ & Arrive at the B2B customer unloading land. & $\mathrm{T}_{7}$ & Inspect loading operation \\
$\mathrm{P}_{8}$ & B2B customer inspection finished & $\mathrm{T}_{8}$ & Delivery and transportation \\
& & $\mathrm{T}_{9}$ & B2B customers inspect the goods. \\
& & $\mathrm{T}_{10}$ & B2B customer signing \\
\hline
\end{tabular}

(2) Establishment of B2C business distribution process model.

The Petri net process for building B2C business is similar to B2B.

(3) Establishment of B2B/B2C business distribution process model.

The Petri net process for establishing B2B/B2C business is shown in figure 2:

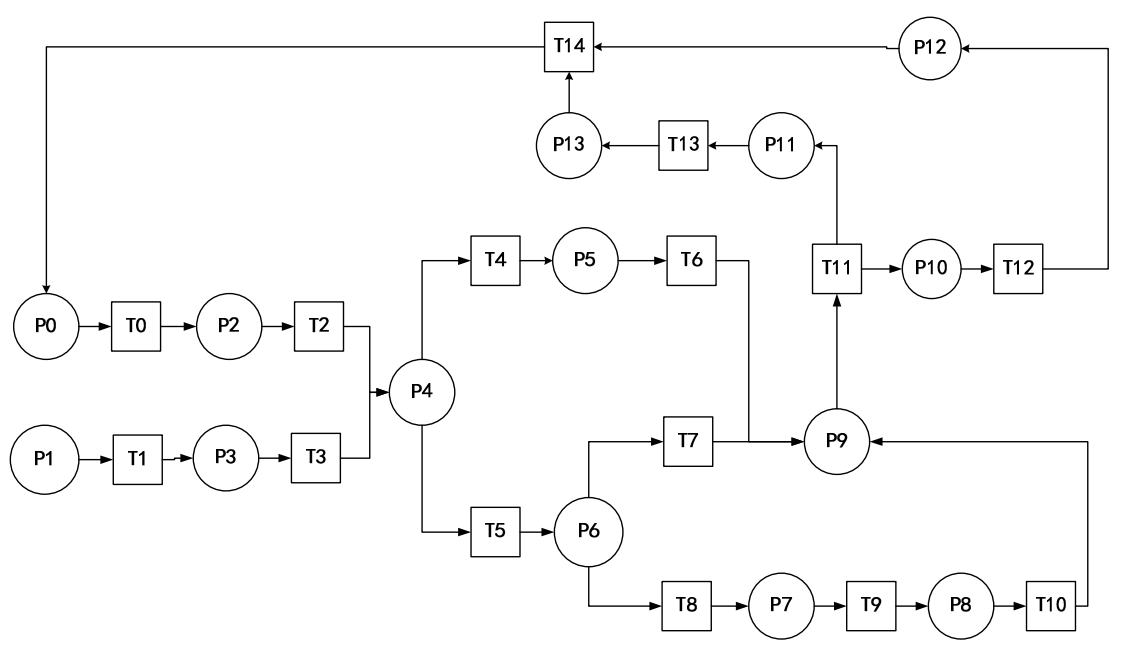

Fig 2. Petri net model of B2B/B2C business distribution process

The contents of each element in the Petri net model of distribution business are shown in table :

Table 2. Meaning of each element in the $\mathrm{B} 2 \mathrm{~B} / \mathrm{B} 2 \mathrm{C}$ distribution process of Petri net

\begin{tabular}{cccc}
\hline $\begin{array}{c}\text { Place } \\
\text { sign }\end{array}$ & The connotation of the place & Transition sign & The connotation of the transition \\
\hline $\mathrm{P}_{0}$ & The customer of B2B & $\mathrm{T}_{0}$ & Send B2B demand orders. \\
$\mathrm{P}_{1}$ & The customer of B2C & $\mathrm{T}_{1}$ & Send B2C demand orders. \\
\hline $\mathrm{P}_{2}$ & Cold chain logistics company. & $\mathrm{T}_{2}$ & Order processing \\
$\mathrm{P}_{3}$ & Cold chain logistics company. & $\mathrm{T}_{3}$ & Order processing \\
$\mathrm{P}_{4}$ & scheduling center & $\mathrm{T}_{4}$ & Call available vehicles \\
$\mathrm{P}_{5}$ & Vehicle arrival at the designated loading site & $\mathrm{T}_{5}$ & Generate waybill of B2B/B2C \\
$\mathrm{P}_{6}$ & warehouse department. & $\mathrm{T}_{6}$ & Waiting for loading \\
$\mathrm{P}_{7}$ & Completion of sorting & $\mathrm{T}_{7}$ & Generate B2B/B2C loading list. \\
$\mathrm{P}_{8}$ & Packaging and processing operations completed & $\mathrm{T}_{8}$ & Sorting operation \\
$\mathrm{P}_{9}$ & Check the loading is completed & $\mathrm{T}_{9}$ & Packaging and processing operations \\
$\mathrm{P}_{10}$ & Arrive at B2C customer point. & $\mathrm{T}_{10}$ & Inspection loading operation \\
$\mathrm{P}_{11}$ & Arrive at B2B customer point. & $\mathrm{T}_{11}$ & Delivery and transportation \\
$\mathrm{P}_{12}$ & B2C customer inspection finished & $\mathrm{T}_{12}$ & $\mathrm{~B} 2 \mathrm{C}$ customers inspect the goods. \\
$\mathrm{P}_{13}$ & B2B customer inspection finished & $\mathrm{T}_{13}$ & $\mathrm{~B} 2 \mathrm{~B}$ customers inspect the goods. \\
& & $\mathrm{T}_{14}$ & Sign \\
\hline
\end{tabular}


In the established B2B/B2C integrated Petri net model, there is a Token in $\mathrm{P} 0$ and $\mathrm{P} 1$ respectively, and Token is transferred from one position to the next, indicating the beginning and end of the action of the position.

\section{Simulation Analysis Based on the Empirical Petri net Model}

By incidence matrix analysis method to the established process reengineering behavior characteristics of Petri net model respectively before and after the inspection, this paper is verified the rationality of the process model and the correctness of this chapter will choose wide application interface simple and clear ARENA software for basic Petri net model for the simulation of the ARENA simulation process flow model is established for the analysis of input simulation parameters debug output analysis simulation model simulation operation.

This chapter will W food logistics company's actual operating data of Beijing as an example, according to the simulation process, selecting reengineering process before and after the running time of the resource utilization process simulation running costs such as changes of the indexes were analyzed.

The behavior characteristics of the Petri net model established before and after the process reengineering are verified by the method of incidence matrix, which verifies the rationality and correctness of the process model in this paper. This chapter will use the ARENA software with a wide range of applications and simple and clear interface to simulate the Petri network model. The basic simulation process of ARENA is the input analysis - establishing the process model - determining the simulation parameters - the debug simulation model - the simulation run - output analysis.

\subsection{Company Background Introduction}

The simulation running cost including transportation cost and damage cost. Through the research of food logistics co., LTD., Beijing W, B2B business separate distribution B2C business distribution and $\mathrm{B} 2 \mathrm{~B} / \mathrm{B} 2 \mathrm{C}$ business integration with vehicles are 4 meters 2 van, refrigerated trucks, daily every car on the grid, the fuel cost is $1.2 \mathrm{Yuan} / \mathrm{km}$, the rest of the cost parameters are as follows

(1) The B2B business is delivered separately.

$\mathrm{B} 2 \mathrm{~B}$ business distribution vehicle 30 vehicles; the maintenance cost of each car is 381.6 Yuan/year; the number of cycles per day is $130 \mathrm{~km}$; the annual loss rate is $0.1 \%$, and the monthly loss cost is 3,375 Yuan.

(2) B2C business is delivered separately.

B2C business distribution vehicle 15 vehicles; The maintenance cost of each car is 381.6 Yuan/year; The cycling time is $100 \mathrm{~km}$ daily; The annual loss rate is $0.1 \%$, and the monthly loss cost is 750 Yuan.

(3) B2B/B2C business integration.

35 vehicles for B2B/B2C businesses; The maintenance cost of each car is 381.6 Yuan/year; The average daily running of the cycle is $150 \mathrm{~km}$; The annual loss rate is $0.07 \%$, and the monthly loss cost is 1,155 Yuan.

\subsection{Analysis of Simulation Results}

The preset Replication Length (simulation run time) is $720 \mathrm{~h}$, i.e., the simulation operation of the model is conducted within one month (30 days), and the simulation results are completed after 10 simulation experiments.

In order to facilitate comparison and analysis of simulation results before and after the reengineering of urban food cold chain logistics distribution, the above simulation results are summarized as shown in table 3. 
Table 3. Comparison of simulation results

\begin{tabular}{c|c|c|c}
\hline \multirow{2}{*}{} & \multicolumn{2}{|c|}{ Before the process of reengineering } & \multirow{2}{*}{ After the process of reengineering } \\
\cline { 2 - 3 } & B2B & B2C & 3.9695 \\
\hline Value-added job duration(h) & 1.7899 & 2.4295 & 10.7671 \\
\hline Total Time(h) & 7.2917 & 4.7565 & 83 \\
\hline Vehicle Usage(\%) & 72 & 35 & 49955.0033 \\
\hline
\end{tabular}

The analysis of relevant data changes before and after reconstruction is as follows:

(1) VA Time.

Process reengineering after fusion with mode of B2B/B2C VA Time is 3.9695 hours, than B2B business and B2B business process reengineering ago VA Time increased 2.1796 hours and 2.1796 hours respectively, after reengineering process simulation of VA Time increases, showed that after the reconstruction of $\mathrm{B} 2 \mathrm{~B} / \mathrm{B} 2 \mathrm{C}$ integration with the process of waiting in line and non-value-added operations duration has been effectively reduced, the process reengineering was improved in the past separate distribution of $\mathrm{B} 2 \mathrm{~B}$ and $\mathrm{B} 2 \mathrm{C}$ business process;

(2) Total Time.

From the simulation results can be observed, before the process reengineering, the general simulation run length is 12.0482 hours, process reengineering, total simulation run length is 10.7671 hours after than constructing the shipping process before the total elapsed time shortened about 1.3 hours. This shows that through the process reengineering, the process efficiency of the regenerated $\mathrm{B} 2 \mathrm{~B} / \mathrm{B} 2 \mathrm{C}$ integration is better than the efficiency of the $\mathrm{B} 2 \mathrm{~B}$ business and $\mathrm{B} 2 \mathrm{C}$ business process before re-engineering, namely, the delivery efficiency is improved.

(3) Vehicle Usage.

Beijing W food distribution co., LTD., in the actual operation process, the distribution of the same value of $\mathrm{B} 2 \mathrm{~B}, \mathrm{~B} 2 \mathrm{C}$ commodity distribution business case distribution trains a day, from before the process reengineering after 45 trains reduced to process reengineering $\mathrm{B} 2 \mathrm{~B} / \mathrm{B} 2 \mathrm{C}$ fusion, a total of 35 trains. Shown in the results of simulation analysis, process reengineering before distribution vehicle full are B2B business alone is $72 \%$, only $35 \%$ of B2C business distribution vehicle full are separately, and after the process reengineering vehicle load factors was $83 \%$, increased by $13 \%$. When the vehicle carrying capacity is increased, it can reduce the number of car trips, which is consistent with the actual situation.

(4) Total Cost.

The total cost of simulation operation before process reengineering is 75352.6972 Yuan, and the simulation operation cost after the process reengineering is 49955.0033 Yuan, which is $33.71 \%$ lower than the total cost of simulation before the process reengineering. Due to the combination of $\mathrm{B} 2 \mathrm{~B} / \mathrm{B} 2 \mathrm{C}$ integration, reducing the number of car trips and reducing the cost of transportation and cost of goods, the total cost of $\mathrm{B} 2 \mathrm{~B} / \mathrm{B} 2 \mathrm{C}$ integration is reduced.

Based on the analysis of the above results show that the use of advanced technology equipment, cold chain logistics process reengineering to improve the efficiency of enterprise's distribution, vehicle load factors have significant effect, but also illustrate the B2B/B2C fusion of the reconstruction design process is effective and reasonable. Through BPR, the enterprise's distribution process has been improved effectively.

\section{Conclusions}

In the example of $\mathrm{W}$ company, Petri modeling method and Arena simulation technology are used to verify the feasibility of the B2B/B2C fusion. However, the paper focused little on the process changes that may occur after blending, and the changes in organizational structure are not studied. In 
the future, I intend to continue to deepen the change of organizational structure and distribution details such as distribution path replanting, so as to realize the true integration of $\mathrm{B} 2 \mathrm{~B} / \mathrm{B} 2 \mathrm{C}$, rather than simply put them together.

\section{References}

[1]. Lei Goo. Research on the Cold Chain Logistics Enterprise Distribution Process Optimization Based on Petri Net. [D]. Beijing Jiao tong University, 2010.

[2]. Chongjin Yuan. Petri net application [M]. Science press, 2013.

[3]. Xin Li. Logistics system modeling and simulation. [M]. Shanghai people's publishing house. 2013.

[4]. Wan Xuan Wang. Research on Business Process Reengineering of Urban Freight Based on Technology of Mobile Internet [D]. Beijing Jiao tong University, 2016.

[5]. Zora Li. Research on the Policy of Home-delivery for food based on E-commerce [D]. Southwest Jiao tong University, 2016.

[6]. Sanjay Sharma, Ushant Scathes Pay. Analysis of operating effectiveness of a cold chain model using Bayesian networks [J], Business Process Management Journal, 2015, Vol.21:722-742.

[7]. Remit Joshi, Divider Kumar Ban wet, and Ravi Shankar. Indian cold chain: modelling the inhibitors [J], British Food Journal, 2009, Vol. 111:1260-1283.

[8]. Michael Lütjen, Patrick Dittmer, Marius Viet. Quality driven distribution of intelligent containers in cold chain logistics networks [J], German Academic Society for Production Engineering (WGP) 2013:291-297. 